\title{
Hydroxylation index of omeprazole in relation to CYP2C19 polymorphism and sex in a healthy Iranian population
}

\author{
Maryam Payan ${ }^{1}$, Mohammad Reza Rouini ${ }^{*}$, Nader Tajik², Mohammad Hossein Ghahremani ${ }^{3}$ and Reza Tahvilian ${ }^{4}$
}

\begin{abstract}
Background: Polymorphism of CYP2C19 gene is one of the important factors in pharmacokinetics of CYP2C19 substrates. Omeprazole is a proton pump inhibitor which is mainly metabolized by cytochrome P450 2C19 (CYP2C19). The aim of present study was to assess omeprazole hydroxylation index as a measure of CYP2C19 activity considering new variant allele (CYP2C19*17) in Iranian population and also to see if this activity is sex dependent.

Methods: One hundred and eighty healthy unrelated Iranian individuals attended in this study. Blood samples for genotyping and phenotyping were collected 3 hours after administration of $20 \mathrm{mg}$ omeprazole orally. Genotyping of 2C19 variant alleles ${ }^{*},{ }^{*} 3$ and ${ }^{*} 17$ was performed by using polymerase chain reaction-restriction fragment length polymorphism (PCR-RFLP) and semi-nested PCR methods. Plasma concentrations of omeprazole and hydroxyomeprazole were determined by high performance liquid chromatography (HPLC) technique and hydxroxylation index (HI) (omeprazole/ hydroxyomeprazole) was calculated.
\end{abstract}

Results: The CYP2C19*17 was the most common variant allele in the studied population (21.6\%). Genotype frequencies of CYP2C19*17*17, ${ }^{*} 1^{*} 17$, and ${ }^{*} 2^{*} 17$ were $5.5 \%, 28.8 \%$ and $3.3 \%$ respectively. The lowest and the highest median omeprazole $\mathrm{HI}$ was observed in ${ }^{*} 17^{*} 17$ and ${ }^{*} 2^{*} 2$ genotypes respectively (0.36 vs. 13.09). The median $\mathrm{HI}$ of omeprazole in subjects homozygous for CYP2C19*1 was 2.16-fold higher than individuals homozygous for CYP2C19*17 (P<0.001) and the median HI of CYP2C19*1*17 genotype was 1.98-fold higher than CYP2C19 ${ }^{*} 17^{*} 17$ subjects $(\mathrm{P}<0.001)$. However, subjects with CYP2C19*2*17 (median HI: 1.74) and CYP2C19*1*2 (median HI: 1.98) genotypes and also CYP2C19*1*17 (median HI: 0.71) and CYP2C19*1*1 (mean HI: 0.78) did not show any significantly different enzyme activity. In addition, no statistically significant difference was found between women and men in distribution of CYP2C19 genotypes. Furthermore, the hydroxylation index of Omeprazole was not different between women and men in the studied population.

Conclusion: Our data point out the importance of CYP2C19*2 and CYP2C19*17 variant alleles in metabolism of omeprazole and therefore CYP2C19 activity. Regarding the high frequency of CYP2C19*17 in Iranian population, the importance of this new variant allele in metabolism of CYP2C19 substrates shall be considered.

Keywords: CYP2C19, Enzyme activity, Genotype, Omeprazole, Phenotype

\footnotetext{
* Correspondence: rouini@tumsacir

'Biopharmaceutics and Pharmacokinetics Division, Department of

Pharmaceutics, School of Pharmacy, Tehran University of Medical sciences,

Tehran, Iran

Full list of author information is available at the end of the article
} 


\section{Introduction}

Cytochrome P450 includes a wide variety of phase I metabolizing enzymes which are involved in metabolism of drugs and endogenic substances [1,2]. CYP2C19 is one of the members of cytochrome iso enzyme superfamily which contributes in metabolism of important drugs such as proton pump inhibitors (PPI) [3] psychotic drugs like venlafaxine [4] and citalopram [5,6], voriconazol [7], and clopidogrel $[8,9]$.

CYP2C19 is represented by a gene located on chromosome 10 [10]. Genetic polymorphism of CYP2C19 is one of the major reasons of inter-individual variability in response to CYP2C19 substrate [11-13]. The main CYP2C19 polymorphisms that are associated with difference in therapeutic response are attributed to CYP2C19*2, CYP2C19*3 and $C Y P 2 C 19 * 17[14,15]$.

A point mutation in exon 5 (681 G>A, designated *2) causes a cryptic splice defect $\left(C Y P 2 C 19^{*} 2\right)$ and a single nucleotide polymorphism (SNP) in exon 4 (636 G>A designated *3) creates a stop codon. Both mutations predominantly result in decreased CYP2C19 activity $[9,16]$. A recently discovered SNP in $5^{\prime}$-flanking region (-806 $C>T$ and $-3402 C>T$ ) leads to increased CYP2C19 activity and therefore produces ultra rapid metabolizer phenotype $[17,18]$.

The CYP2C19*2*2 and *3*3 genotypes are more prevalent in oriental and Asian populations than in Caucasian (12-23\% vs $3-5 \%)$. In contrast the CYP2C19*17*17 is more frequent in Caucasian than in Asian populations (18-26\% vs $0.4-1.4 \%)[19,20]$.

Omeprazole is a proton pump inhibitor that is administered in treatment of gastric acid related disease [21]. Polymorphism of CYP2C19 can affect pharmacokinetic and therefore efficacy of proton pump inhibitors [21,22]. Additionally non genetic factors like age, liver disease and combination therapy can result in resistance to Helicobacter Pylori eradication treatment [23,24].

Several studies have used hydroxylation index of omeprazole as an indicator of CYP2C19 activity however this enzyme activity, was mainly measured in relation to * 2 and *3 variant alleles and not the new variant allele (*17) [16,25-28]. Although Sim et al. studied the effect of CYP2C19*17 variant allele on enzyme activity, they only reported this activity in extensive metabolizers $\left({ }^{*} 17^{*} 17\right.$, ${ }^{*} 1 * 17$ and $\left.* 1 * 1\right)$ and they did not determine CYP2C19 activity in CYP2C19*2*17 carriers [17]. CYP2C19*2 leads to decreased enzyme activity and CYP2C19*17 causes increased enzyme activity $[16,17]$ but the impact of combined alleles (CYP2C19*2*17) on CYP2C19 activity has not been reported comprehensively and it is unknown that the effect of which allele is more predominant in $C Y P 2 C 19 * 2 * 17$ carriers.

Furthermore there are some controversies in publications about impact of sex on CYP2C19 activity [29,30].
To our best knowledge, currently there is no published data regarding CYP2C19 activity in relation to new variant allele in Iranian population. Thus, the objects of this study were to assess effect of CYP2C19*17 on enzyme activity and also to see if there is any sex-dependent difference in CYP2C19 activity and finally to investigate genotypephenotype relationship of CYP2C19 considering new variant allele (CYP2C19*17) in Iranian population.

\section{Material and methods \\ Study subjects}

The study protocol was approved by ethics committee of Tehran University of Medical Sciences (ethical no. 11208). Generally one hundred and eighty (60 women and 120 men) unrelated healthy Iranian volunteers with the mean age of between 20-55 years and average body weight of 45-89 $\mathrm{kg}$ took part in this study. All participants signed written informed consent of this project. The study was completed by contribution of faculties of pharmacy of Tehran, Yazd, Kermanshah and Kerman University of Medical Sciences. The participants were students or stuffs of pharmacy schools, with no history of any illness or medicine consumption. No smoking and consumption of medicine that would affect CYP2C19 activity was permitted for one week before and during the study.

\section{CYP2C19 phenotyping}

After an overnight fast for at least 8 hours, volunteers took $20 \mathrm{mg}$ omeprazole capsule (Abidi pharmaceuticals) with 250 milliliter tap water. Ten $\mathrm{ml}$ venous blood sample was collected from each subject 3 hours after administration of omeprazole and transferred into tubes containing $10 \mu \mathrm{l}$ of $10 \%$ EDTA. Five $\mathrm{ml}$ of blood samples were centrifuged for $5 \mathrm{~min}$ at $4000 \mathrm{rpm}$ and the plasma was separated and transferred to Eppendorf tube and stored at $-80^{\circ} \mathrm{C}$ up to the day of analysis. The other $5 \mathrm{ml}$ blood samples were stored directly in $-80^{\circ} \mathrm{C}$ for genotyping analysis.

\section{Analytical procedure}

Omeprazole powder was purchased from TMAD (Iran). 5-hydroxyomeprazole was a kind donation by AstraZeneca (Sweden). The concentration of omeprazole and 5hydroxyomeprazole was analyzed by HPLC method as described by Rezk et al. with a few modifications [31]. Briefly $500 \mu \mathrm{l}$ plasma was extracted by liquid-liquid extraction using $1500 \mu \mathrm{l}$ ethyl acetate. After orbital mixing for $10 \mathrm{~min}$ and centrifuging at $4000 \times \mathrm{g}$ for $10 \mathrm{~min}$, the upper organic layer was separated and transferred to glass tube and then evaporated to dryness under gentle stream of air. Finally the residue was dissolved in $250 \mu \mathrm{l}$ mobile phase and $100 \mu \mathrm{l}$ of this sample was injected to HPLC system. The mobile phase was a combination of 
dibasic sodium phosphate buffer (0.025 mol/lit, $\mathrm{pH}$ 6): acetonitrile: methanol (73: 18: $8 \mathrm{~V} / \mathrm{V} / \mathrm{V})$. The HPLC apparatus consisted of a low pressure HPLC pump, UV detector $(\lambda=302 \mathrm{~nm})$ all from Knauer (Berlin, Germany). The chromatographic separation was performed by using Chromolit $^{\mathrm{TM}}$ Performance RP-18e $100 \mathrm{~mm} \times 4.6 \mathrm{~mm}, 5 \mu \mathrm{m}$ particle size. Flow rate was adjusted to $1 \mathrm{ml} / \mathrm{min}$. The limits of quantification were about $15 \mu \mathrm{g} / \mathrm{ml}$ for both compounds. Intraday and between day precisions were $<5 \%$ for both omerpazole and 5-hydroxyomeprazole.

\section{CYP2C19 genotyping}

The DNA was extracted from blood leucocytes by standard salting out method as explained by Miller et al. [32]. The extracted DNA was dissolved in sterile distilled water and stored at $4{ }^{\circ} \mathrm{C}$ until the day of analysis. Amplification of CYP2C19*2 and *3 allele was implemented using polymerase chain reaction-restriction fragment length polymorphism (PCR-RFLP) as described by De Morias [33]. The PCR product of each reaction was digested by specific endonuclease (all from New England Biolabs GmbH, Frankfurt, Germany); the 169 bp CYP2C19*2 product was digested by SmaI to 40 and $129 \mathrm{bp}$ fragments. The $329 \mathrm{bp}$ PCR product of CYP2C19*3 was digested by BamHI to 233 and 96 bp pieces. Genotyping of $C Y P 2 C 19 * 17-3402 C>T$ and $-806 C>T$ polymorphisms was done by PCR-RFLP and nested-PCR assays as defined by $\mathrm{Sim}$ et al. [17]. For CYP2C19*17 -3402 C>T the PCR product ( $504 \mathrm{bp}$ ) was digested by MnlI and resulted in 224 and 280 bp fragments. But the PCR product of $C Y P 2 C 19 * 17-806 C>T(200 \mathrm{bp})$ was separated directly on $2.5 \%$ agarose gel without any digestion. In all PCRRFLP assays mutation caused abolishment of restriction site and thus PCR product was not digested.

\section{Statistical analysis}

The allele frequencies differences between population were estimated using two-tailed Fisher's exact test. The 95\% confidence intervals (CI) were calculated using Confidence Interval Analysis software. The relation of sex and genotype was assessed by two tailed Fisher's exact test. The observed and expected frequencies were calculated by using Hardy-Weinberg equation. The two-tailed Fisher's exact test was used to evaluate deviation of genotype frequencies in the studied population from Hardy-Weinberg equilibrium. The enzyme activity was compared by using omeprazole hydroxylation index. The hydroxylation index (HI) of omeprazole 3 hours after administration of omeprazole was calculated by dividing omeprazole to 5hydroxyomeprazol plasma concentration. The mean $\mathrm{HI}$ in different genotypes were compared by Mann-Whitney two tailed test. The impact of sex on HI of omeprazole was also evaluated using Mann-Whitney two tailed test. The inter-individual variability in metabolism of omeprazole was represented by probit plot. For drawing probit plot, the log of HI was calculated, the antimode value was determined using Microsoft office excel 2010. The normality of $\mathrm{HI}$ distribution was analyzed by frequency distribution histogram and also by KolmogorovSmirnov test. All statistical analyses were performed by Sigma Plot version 12.0 and Graph Pad Prism version 5 softwares and $\mathrm{P}<0.05$ was considered as statistically significant difference.

\section{Results}

The genotype and allele frequencies of CYP2C19 are reported in Table 1. According to the data presented in Table 1, CYP2C19 $* 17 * 17$, $1 * 17$ and $* 1 * 1$ were detected in $10(5.5 \%), 52(28.9 \%)$ and $75(41.7 \%)$ subjects respectively. The CYP2C19*2*17 and * $1 * 2$ were identified in $6(3.3 \%)$ and $33(18.3 \%)$ individuals and finally the $C Y P 2 C 19 * 2 * 2$ was recognized in $4(2.2 \%)$ of volunteers. CYP2C19*17 was the most common variant allele in Iranian population.

The hydroxylation index of omeprazole as mean $\pm \mathrm{SD}$, median and $95 \%$ confidence interval is reported in Table 2. Subjects with CYP2C19 *17*17 genotype had a very high metabolic capacity with median hydroxylation index of 0.36 and were classified as Ultra-Rapid Metabolizers (URM). The median hydroxylation index of omeprazole in subjects homozygous for CYP 2 C19*1 was 2.17 fold higher than individual homozygous for CYP2C19*17 $(\mathrm{P}<0.001)$ and the median hydroxylation index of $C Y P 2 C 19 * 1 * 17$ genotype was 1.97 fold higher than $C Y P 2 C 19 * 17 * 17$ subjects $(\mathrm{P}<0.001)$. There was not a significant difference between $\mathrm{HI}$ of omeprazole in $C Y P 2 C 19 * 1 * 17$ and $* 1 * 1$ carriers $(\mathrm{P}>0.05)$ and these two groups were stratified as extensive metabolizers (EM).

The median HI of omeprazole was 1.74 in CYP2C19*2*17 and 1.98 in CYP2C19*1*2 carriers respectively. The difference in $\mathrm{HI}$ of omeprazole in CYP2C19*1*2 carriers were statistically significant with other CYP2C19 genotypes $(\mathrm{P}<0.05)$ except for CYP2C19*2*17 genotype $(\mathrm{p}>0.05)$. Individuals in these two groups had intermediate metabolic capacity and were designated as IntermediateMetabolizers (IM). Homozygous carrier of CYP2C19*2 had a very low metabolic capacity with the median hydroxylation index of 13.03 and they were classified as poor metabolizers (PM). There was a significant difference between $\mathrm{HI}$ index of homozygous carriers of CYP2C19*2 with the other five genotypes $(\mathrm{p}<0.001)$.

The plasma concentration of omeprazole and hydroxyomeprazole is illustrated in Figure 1. According to this figure there is a significant difference between omeprazole plasma concentration in individuals with CYP2C19*17*17 genotype with all other groups $(\mathrm{P}<0.01)$, but the omeprazole plasma concentration was neither different between $1 * 17$ and $1 * 1(\mathrm{EM})(\mathrm{P}>0.5)$ nor between $2 * 17$ and $1 * 2$ (IM) 
Table 1 Genotype and allele frequencies of CYP2C19 in 180 healthy Iranian volunteers

\begin{tabular}{|c|c|c|c|c|}
\hline \multirow{2}{*}{$\begin{array}{l}\text { CYP2C19 } \\
\text { Genotype }\end{array}$} & \multicolumn{2}{|c|}{ Number of subjects } & \multirow[t]{2}{*}{ Frequency (\%) } & \multirow[t]{2}{*}{$95 \% \mathrm{Cl}$} \\
\hline & Men (120) & Women (60) & & \\
\hline$* 17 * 17$ & 5 & 5 & 5.5 & $2.7-10.0$ \\
\hline$*^{*}{ }^{*} 17$ & 37 & 15 & 28.8 & $22.4-36.1$ \\
\hline${ }^{*} 1^{* 1}$ & 53 & 22 & 41.7 & $34.4-49.2$ \\
\hline$*^{*} *^{*} 2$ & 20 & 13 & 18.3 & $13.0-24.7$ \\
\hline$* 2 * 17$ & 4 & 2 & 3.3 & $1.23-7.1$ \\
\hline$*^{*} 2$ & 1 & 3 & 2.2 & $0.6-5.5$ \\
\hline CYP2C19 Alleles & \multicolumn{2}{|l|}{ No. of alleles } & Frequency (\%) & $95 \% \mathrm{Cl}$ \\
\hline CYP2C19*17 & \multicolumn{2}{|l|}{78} & 21.6 & $17.5-26.3$ \\
\hline CYP2C19*1 & \multicolumn{2}{|l|}{235} & 65.3 & $60.1-70.2$ \\
\hline CYP2C19*2 & \multicolumn{2}{|l|}{47} & 13.1 & $9.7-16.9$ \\
\hline CYP2C19*3 & \multicolumn{2}{|l|}{0} & 0 & 0 \\
\hline
\end{tabular}

*Cl: Confidence Interval. (The 95\% confidence intervals (Cl) were calculated using Confidence Interval Analysis software).

genotypes. However, omeprazole plasma concentration was significantly different between EM $(1 * 17$ and $1 * 1)$ and IM $(2 * 17$ and $1 * 2)$. The plasma concentration of hydroxyomeprazole was significantly different between $* 2 * 2$ and all other 5 genotypes while the plasma concentration of hydroxyomeprazole was not significantly different between other 5 genotypes $\left(17 * 17,1 * 17,{ }^{*} 1 * 1,2 * 17,1 * 2\right)$.

Figure 2 indicates the hydroxylation index of omeprazole in 6 genotypes and also in predicted phenotype groups. As it is observed there is no significant difference between hydroxylation index of omeprazole in $1 * 17$ and $1 * 1$ groups or between $2 * 17$ and $1 * 2$ groups. While the difference between $17 * 17$ or $2 * 2$ with all other genotype groups were statistically significant.

The summary of omeprazole, hydroxyomeprazole plasma concentration and omeprazole $\mathrm{HI}$ in the total population, women and men is reported in Table 3. Omeprazole plasma concentration was significantly higher in $2 * 2$ genotype than other genotype groups. Additionally there was a significant difference in omeprazole plasma concentration between different groups $(\mathrm{P}<0.001)$ except for CYP2C19*1*17 and *1*1 (P > 0.05), CYP2C19*1*2 and CYP2C19*2*17 ( $>0.05)$. Mean omeprazole plasma concentration was 19.0 fold higher in CYP2C19*2*2 than CYP2C19*17*17 and 11 fold higher than CYP2C19*1*1 $(\mathrm{P}<0.001)$, however hydroxyomeprazole concentration was not statistically different among genotype groups ( $\mathrm{P}>0.05$ ) except for CYP2C19*2*2. Moreover, omeprazole and hydroxyomeprazole plasma concentrations as well as omeprazole HI were not statistically different among women and men in the studied population $(\mathrm{P}>0.05)$.

The effect of sex on hydroxylation index of omeprazole is illustrated in Figure 3. According to this figure there is not any significant difference between median hydroxylation index in women (0.84) and men (0.86) ( $p>0.05)$.

The frequency distribution histogram of omeprazole hydroxylation index in 180 healthy Iranian volunteers is indicated in Figure 4. The graph shows a bimodal distribution with the antimode of around 0.8. KolmogorovSmirnov test showed that the omeprazole hydroxylation index was not normally distributed in the studied population (K-S Dist. $=0.296 \mathrm{p}<0.001$ ). The bimodal distribution was also confirmed by probit plot.

The correlation of CYP2C19 genotype and phenotype was tested using Spearman rank correlation, and the results showed a well correlation between CYP2C19 genotype and phenotype $\left(\mathrm{r}_{\mathrm{s}}=0.64, \mathrm{P}<0.0001\right)$.

\section{Discussion}

Inter-individual variability in drug response always has been one of the main concerns in drug discovery and development. The important factors resulting in such

Table 2 Hydroxylation index of omeprazole (omeprazole/hydroxyomeprazole) in relation to CYP2C19 genotype in 180 healthy Iranian subjects

\begin{tabular}{|c|c|c|c|c|c|c|}
\hline & $* 17 * 17$ & $* 1 * 17$ & $* 1 * 1$ & ${ }^{*} 2 * 17$ & $* 1 * 2$ & $* 2 * 2$ \\
\hline Mean (SD) & $0.35(0.06)$ & $0.75(0.28)$ & $0.85(0.30)$ & $2.02(0.84)$ & $2.27(1.04)$ & 13.59(3.13) \\
\hline Median & $0.36^{\mathrm{a}}$ & 0.71 & 0.78 & $1.74^{\mathrm{b}}$ & $1.98^{\mathrm{b}}$ & $13.03^{\mathrm{a}}$ \\
\hline $95 \% \mathrm{Cl}$ & $0.31-0.39$ & $0.68-0.83$ & $0.79-0.92$ & $1.33-2.72$ & $1.92-2.63$ & $10.51-16.67$ \\
\hline
\end{tabular}

${ }^{\mathrm{a}}$ Represent statistically significant difference with other 5 genotypes.

${ }^{b}$ Represent statistically significant difference with $* 17 * 17,{ }^{*} 1 * 17, * 1 * 1$ and $* 2 * 2$.

$\mathrm{Cl}$ : Confidence Interval. 


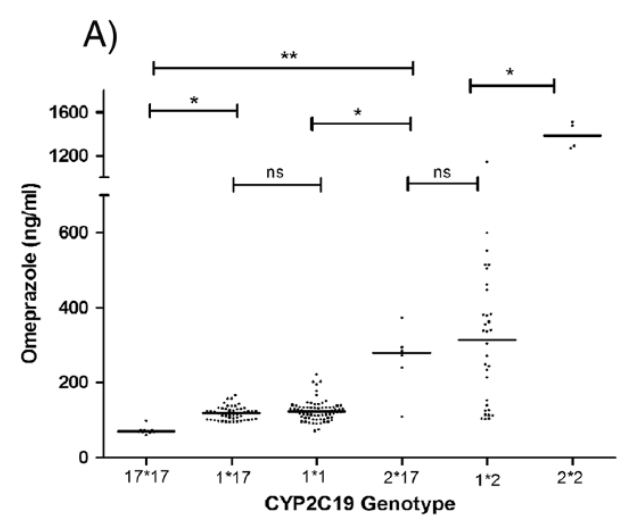

B)

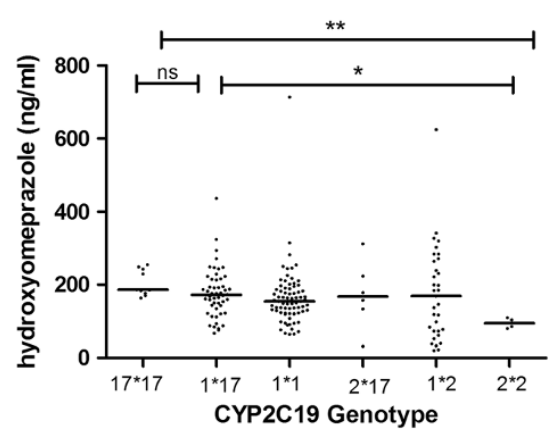

Figure 1 Plasma concentrations of Omeprazole (A) and hydroxyomerpazole (B) in different genotypes 3 hours after administration of Omeprazole orally. ns: not significant, ${ }^{*} p<0.05,{ }^{* *} p<0.001$.

variation include genetic, nongenetic and physiologic agents like change in protein structure, combination therapy, alcohol, smoking, sex, age and disease condition [34].

CYP2C19*17 is a new variant allele which is associated with increased gene transcription and therefore higher enzyme activity [17]; which may lead to several clinical consequences including the lower susceptibility to breast cancer risk [35], higher risk of peptic ulcer disease [36], greater response to clopidogrel treatment and more risk of bleeding [37] in addition to a better treatment with tamoxifen [38].

In this study, omeprazole HI after 3 hours administration of omeprazole was used as indicator of CYP2C19 activity. The $\mathrm{HI}$ in CYP2C19*17*17 was significantly different with CYP2C19*1*17 and CYP2C19*1*1 genotypes and people in this group had very high metabolic activity, which is in agreement with what was reported by Sim et al. They found that median HI of omeprazole in homozygous carriers of CYP2C19*1 is 2 fold higher than homozygous carriers of CYP2C19*17 and 1.2 fold higher than CYP2C19*1*17 [17]. Ramsjö et al. has also reported that mean $\mathrm{HI}$ of omeprazole in CYP2C19*1*1 was 3.2 fold higher than CYP2C19*17*17 and 1.1 fold higher than CYP2C19*1*17 [27].

CYP2C19*2 allele is associated with decreased enzyme activity and $C Y P 2 C 19^{*} 17$ variant allele is connected with increased enzyme activity. In Most of the genotype phenotype studies of CYP2C19*17 variant allele, only $\mathrm{HI}$ of omeprazole in CYP2C19*17*17, CYP2C19*1*17 and CYP2C19*1*1 genotypes has been reported $[17,27]$. However, the capacity of CYP2C19 enzyme activity in people carrying both defective mutant alleles of $* 2$ and "17 (CYP2C19*2*17) was still unclear. Although Ragia et al. in the study for evaluation of distribution of CYP2C19*17 genetic polymorphism in Greece people defined CYP2C19*2*17 carriers as EM and people with CYP2C19*1*2 as IM, they only predicted phenotype based on genotype and CYP2C19 activity was not determined by using a probe drug [39]. Sugimito et al. did not see any difference between metabolic capacities of CYP2C19*1*1, *1*17, 2*17 and $1 * 2$ for metabolism of
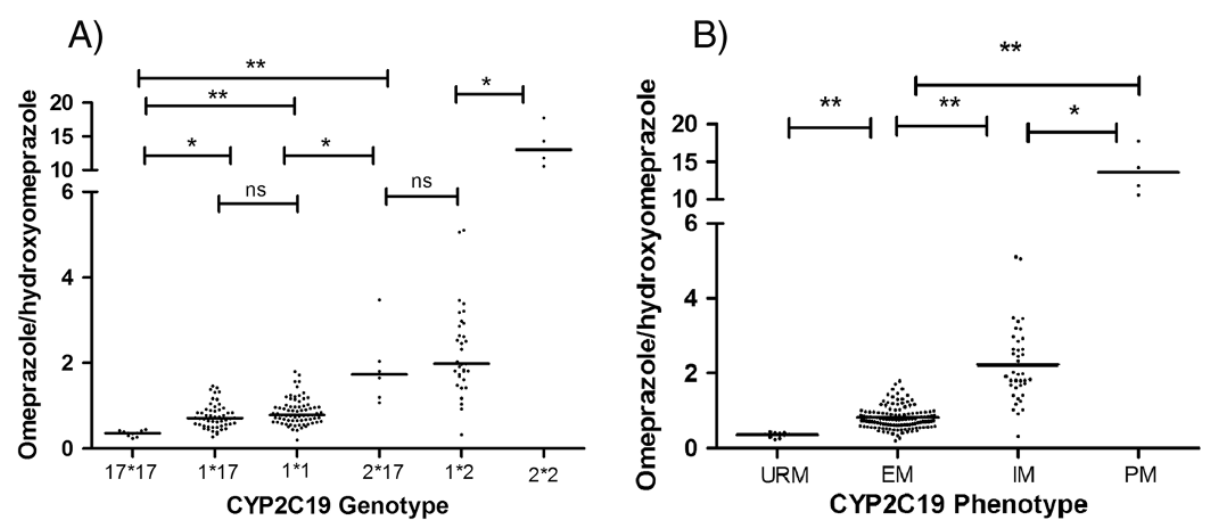

Figure 2 The hydroxylation index of Omeprazole in different genotypes (A) and in predicted phenotype groups (B) 3 hours after administration of Omeprazole orally. ns: not significant, ${ }^{*} p<0.05$, ${ }^{* *} p<0.001$. 
Table 3 Plasma concentration of omeprazole (OMP) and hydroxyomeprazole (OH-OMP) and hydroxylation index (HI) of omeprazole in relation to genotype in 60 women and 120 men 3 hour after administration of single oral dose of 20 mg omeprazole

\begin{tabular}{lllll}
\hline Genotype & No of subjects & Mean OMP concentration $(\mathbf{n g} / \mathbf{m l}) \pm$ SD & Mean OH-OMP concentration $(\mathbf{n g} / \mathbf{m l}) \pm$ SD & Mean HI \pm SD \\
\hline $17^{* 17}$ & Total (10) & $71.01 \pm 10.28$ & $203.31 \pm 34.93$ & $0.35 \pm 0.06$ \\
& Women (5) & $68.32 \pm 5.73$ & $204.92 \pm 41.35$ & $0.34 \pm 0.08$ \\
& Men (5) & $73.71 \pm 13.67$ & $201.69 \pm 32.08$ & $0.36 \pm 0.04$ \\
$1 * 17$ & Total (52) & $118.28 \pm 10.19$ & $177.05 \pm 37.53$ & $0.75 \pm 0.28$ \\
& Women (15) & $120.22 \pm 20.12$ & $174.51 \pm 28.01$ & $0.72 \pm 0.18$ \\
& Men (37) & $117.49 \pm 16.10$ & $178.07 \pm 44.57$ & $0.77 \pm 0.32$ \\
$1 * 1$ & Total (75) & $124.75 \pm 27.18$ & $163.74 \pm 32.25$ & $0.85 \pm 0.30$ \\
& Women (22) & $128.06 \pm 39.90$ & $194.40 \pm 60.84$ & $0.78 \pm 0.27$ \\
& Men (53) & $123.38 \pm 20.83$ & $151.01 \pm 26.38$ & $0.89 \pm 0.30$ \\
$2 * 17$ & Total (6) & $289.01 \pm 97.45$ & $172.79 \pm 63.58$ & $2.02 \pm 0.54$ \\
& Women (4) & $324.25 \pm 39.90$ & $178.72 \pm 33.59$ & $1.97 \pm 0.62$ \\
& Men (2) & $271.39 \pm 118.56$ & $169.82 \pm 84.95$ & $2.05 \pm 0.67$ \\
$1 * 2$ & Total (33) & $319.45 \pm 150.34$ & $177.79 \pm 38.39$ & $2.27 \pm 1.04$ \\
& Women (13) & $364.92 \pm 265.16$ & $194.66 \pm 52.56$ & $2.24 \pm 0.79$ \\
& Men (20) & $289.89 \pm 167.55$ & $165.53 \pm 23.55$ & $2.29 \pm 1.19$ \\
& Total (4) & $1388.99 \pm 123.41$ & $104.67 \pm 10.55$ & $13.59 \pm 3.13$ \\
& Women (3) & $1359.84 \pm 133.23$ & $105.03 \pm 13.80$ & $13.37 \pm 3.80$ \\
& Men (1) & 1476.4 & 103.58 & 14.25 \\
\hline
\end{tabular}

$\mathrm{HI}=$ (omerpazole concentration/hydroxyomeprazole concentration).

omeprazole and stratified these individuals as EM [20]. The omeprazole $\mathrm{HI}$ in subjects with CYP2C19*2*17 genotype in this study was not significantly different from $C Y P 2 C 19 * 1 * 2$ genotype $(P=0.33)$ so we designated them as IM. It seems that in heterozygous carriers of CYP2C19*2 and "17 allele, the effect of * 2 allele is more predominant than ${ }^{*} 17$ allele and it can suppress induced enzyme activity by " 17 allele. This observation is in agreement with classification of $C Y P 2 C 19 * 2 * 17$ as IM by Gurbel et al. based on the study for genotype phenotype analysis of $2 \mathrm{C} 19$ in stented patient [40]. In contrast to these findings, in a study for evaluation of
CYP2C19 enzyme activity in Turkish children using lansoprazole as a probe drug, individuals with CYP2C19*2*17 had similar enzyme activity to $C Y P 2 C 19 * 1 * 17$ and CYP2C19*1*1; and this activity was significantly different from $C Y P 2 C 19 * 1 * 2$ [41]. Involvement of individual with different age groups could possibly explain such different observations. Our study was conducted in adult individuals with the average age of 32 years but Gumus implemented the study in children with mean age of 10.2 years. The lower frequency of $C Y P 2 C 19 * 2 * 17$ in our studied subjects in comparison to Turkish individuals (6 vs 16) can be considered as another justification.
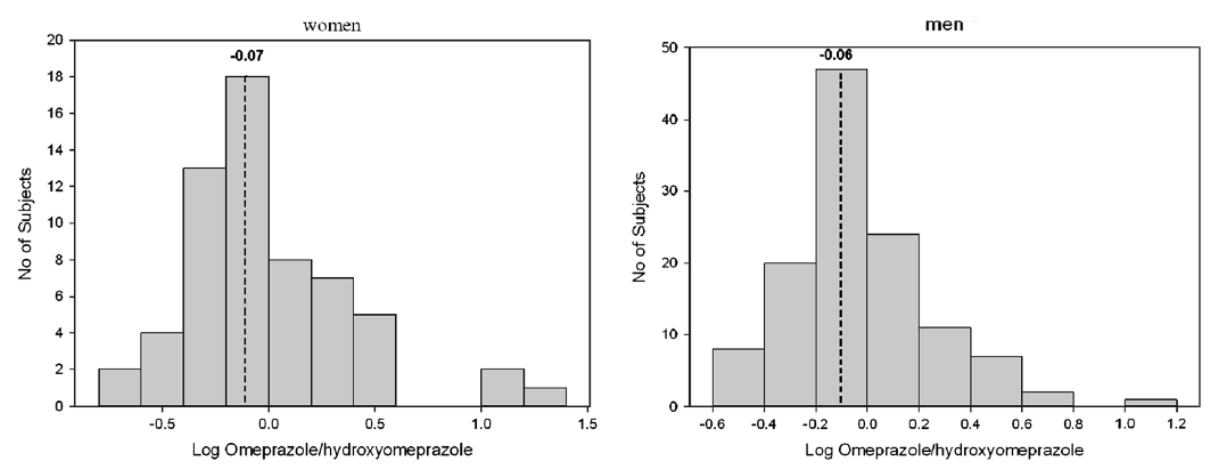

Figure 3 The effect of sex on hydroxylation index of omeprazole in 60 women and $\mathbf{1 2 0}$ men. The median hydroxylation index is indicated by dashed line. 

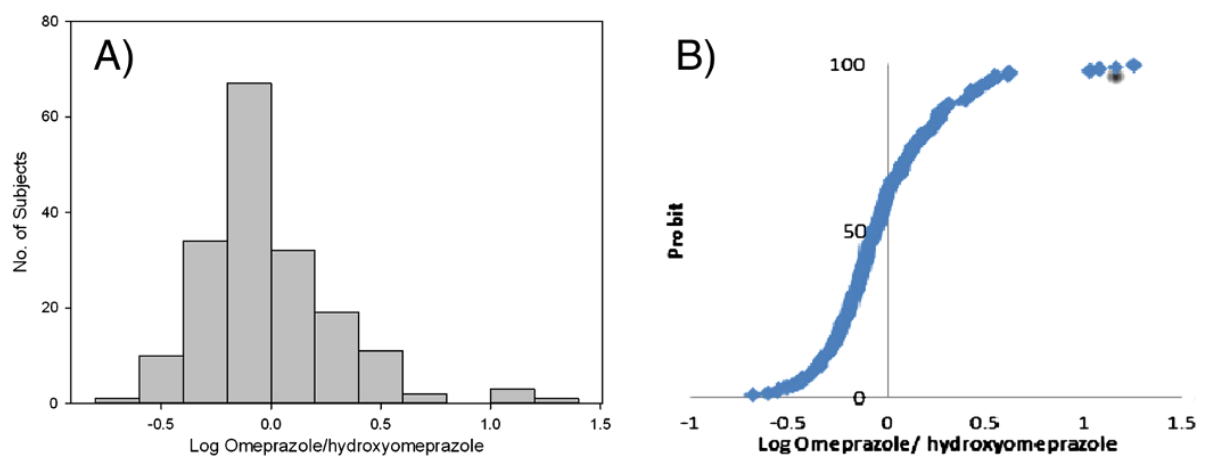

Figure 4 A) Frequency histogram distribution and B) Probit plot of log omeprazole hydroxylation index in 180 healthy Iranian volunteers. Subjects with $\log \mathrm{HI}>1.0$ were phenotyped as poor metabolizers.

In the present study effect of CYP2C19 genetic polymorphism and sex on metabolic activity of CYP2C19 was also assessed. Sex is an important factor in activity of some cytochrome P450 enzymes. CYP3A4 is an example of cytochrome enzymes which has higher activity in women than men [2]. There were some controversies in the previous published reports for impact of sex on CYP2C19 activity. Ramsjö et al. indicated a sex difference in CYP2C19 activity between Korean subjects and not in Swedish volunteers using Omeprazole as a probe drug [27]. Tamminga et al. observed a sex related decreased CYP2C19 activity in women when used mephenytoin as a probe for evaluation of CYP2C19 activity, however the author declared this reduction was more obvious in those who used oral contraceptive [42]. In contrast, Hägg et al. did not see any sex differences in CYP2C19 activity after administration of mephenytoin in Norwegian population [43]. By considering these reports one may conclude that sex dependency of CYP2C19 activity is influenced by environmental and epigenetic factors like diet and ethnic differences. The other possibility can be attributed to some new genetic mutation in some populations which has not been studied well. The result of this study represents no effect of sex on CYP2C19 activity which is in line with what is reported in Swedish and Norwegian population.

The frequency of PM and URM in Iranian population in this study was about $2.2 \%$ and $5.5 \%$ which is close to the study by Zand et al. [44] and other Caucasian population. In previous report by Akhlaghi et al. in Iranian patients with coronary artery disease the genotype frequency of CYP2C19*2\%2 was reported $4.7 \%$ which is quite different from our results [45]. This can be due to difference in studied population (healthy volunteer's vs specific patients). The genotype frequency of CYP2C19*17*17 (URM) was 4\% in Swedish and 3\% in Ethiopian [17], 5.1\% in Danish [19], $3.18 \%$ in Greece [39], 7\% in Saudi Arabian [46] 1.2\% in Indian [16] and $0 \%$ in Japanese, Korean and Thai population $[20,27,47]$. Accordingly the genotype frequency of
CYP2C19*2*2 (PM) is $2.2 \%$ in Danish [19], $2.1 \%$ in Greece [39], 0.4\% in Saudi Arabian [46], 18.4\% in Indian [16] and 18\% in Japanese people [20].

To the best of authors' knowledge, this is the first study evaluating CYP2C19 genotype and phenotype in Iranian population in relation to new variant allele (CYP2C19*17). In the previous report, Zendehdel et al. investigated impact of CYP2C19 on therapeutic efficacy of omeprazole in Iranian patients with erosive reflux esophagitis; patients were genotyped only for CYP2C19*2 and CYP2C19*3, Individuals with HetEM genotype had better response to treatment with omeprazole than EM (95\% vs $43 \%$ successful treatment response respectively) [48]. The high frequency of CYP2C19*17 allele (21.6\%) detected in this study maybe one justification for $50 \%$ resistance rate in the EM group in Iranian patients in previous report. However impact of this variant allele (CYP2C19*17) on the efficacy of PPIs like omeprazole shall be evaluated in controlled clinical trials.

In this study the antimode of 0.8 was calculated for Iranian population. Different antimodes for HI of omeprazole have been reported in different ethnics groups: 14.4 in Indian [16], 7.0 in Koreans [25] and Thai population [47], 0.63 in Colombians [26], and 3.98 in West Mexicans [49]. The calculated antimode for Iranian population is similar to Colombian population, indicating comparable CYP2C19 activity in Iranians and Colombians and faster enzyme activity than Asian people.

A complete genotype phenotype correlation was observed in this study. However it should be noted that enzyme activity and therefore metabolic ratio may vary during some disease condition which may result in discrepancy in genotype-phenotype relationship of specific enzyme. Kimura et al. [50] indicated discordance of genotype-phenotype relationship of omeprazole in 14.5\% of EM patients who had peptic ulcer disease. However this discrepancy was not observed in healthy individuals. Reduced hepatic enzyme activity as a result of old age or liver disease was reported as an explanation for such 
finding. Long term treatment with omeprazole which has auto inhibition effect was the other possibility. Williams et al. [51] also did not see genotype-phenotype relationship of 2C19 using omeprazole in patients with advanced cancer. The authors concluded that increased level of some signaling molecules like interleukin (IL) and tumor necrosis factors (TNF $\alpha$ ) may result in down-regulation of metabolizing enzymes [51,52]. So it should be considered that factors like age, disease state, and concomitant medication may have pronounced effect on enzyme activity. Although omeprazole hydroxylation index has been used as an indicator of CYP2C19 activity, it should be considered that hydroxyomeprazole which is formed by CYP2C19 is further metabolized by CYP3A4 to hydroxyomeprazole sulfone [53] which in turn may indirectly affect the hydroxylation index of omeprazole. Therefore the high concentration of CYP3A4 in liver microsomes of some human can explain the deviation from CYP2C19 genotype and also the sex dependent enzyme activity observed in some ethnic groups [54].

The prevalence of $C Y P 2 C 19 * 2 * 17$ in this study was only $6 \%$ which is a limitation of this study. Future studies to investigate impact of CYP2C19*2*17 genotype on CYP2C19 enzyme activity in larger groups specially by using drugs with narrow therapeutic window is suggested.

In conclusion, the result of this study shows that CYP2C19*2*17 has an intermediate metabolic activity which maybe important for drug dose adjustment regimens for treatment, specially in those having narrow therapeutic indices like clopidogrel. Additionally no effect of sex on CYP2C19 activity was observed in this study. Regarding the high frequency of CYP2C19*17 in Iranian population, the importance of this new variant allele in metabolism of CYP2C19 substrates shall be considered.

\section{Abbreviations \\ CYP2C19: Cytochrome P450 2C19; PCR-RFLP: Polymerase chain reaction- restriction fragment length polymorphism; HPLC: High performance liquid chromatography; HI: Hydxroxylation index; SNP: Single nucleotide polymorphism; URM: Ultra-rapid metabolizers; EM: Extensive metabolizers; IM: Intermediate metabolizers; PM: Poor metabolizers; OMP: Omeprazole; $\mathrm{OH}-\mathrm{OMP}$ : Hydroxyomepazole.}

\section{Competing interests}

The authors declare that they have no competing interests.

\section{Authors' contributions}

M-RR, MP, NT, M-H GH and RT conceived the study. MP performed the experimental work. All authors were involved in data analysis and interpretation. MP prepared the manuscript. All authors read and approved the final version.

\footnotetext{
Acknowledgement

This project was supported by a grant from Tehran University of Medical Sciences. We thank Dr. Kjell Andersson, AstraZeneca, Sweden, for kind donation of pure powder of 5 -hydroxyomeprazole. We are grateful to Dr. Mehdi Ansari Dogaheh, Department of Pharmaceutics, Faculty of Pharmacy, Kerman Medical Sciences and Dr. Mohsen Nabimeybodi, Department of pharmaceutics, Faculty of Pharmacy, Yazd University of Medical Sciences, for kind assistance in collection of blood samples.
}

\section{Author details}

'Biopharmaceutics and Pharmacokinetics Division, Department of Pharmaceutics, School of Pharmacy, Tehran University of Medical sciences, Tehran, Iran. ${ }^{2}$ Cellular and Molecular Research Center (CMRC), Iran University of Medical Sciences, Tehran, Iran. ${ }^{3}$ Department of Pharmacology and Toxicology, School of Pharmacy, Tehran University of Medical sciences, Tehran, Iran. ${ }^{4}$ Department of pharmaceutics, School of Pharmacy, Kermanshah University of Medical Sciences, Kermanshah, Iran.

\section{Received: 17 August 2014 Accepted: 1 December 2014}

\section{References}

1. Sim SC, Nordin L, Andersson TM-L, Virding S, Olsson M, Pedersen NL, Ingelman- Sundberg M: Association Between CYP2C19 Polymorphism and Depressive Symptoms. Am J Med Genet 2010, 153(B):1160-1166.

2. Zanger UM, Schwab M: Cytochrome P450 enzymes in drug metabolism: Regulation of gene expression, enzyme activities, and impact of genetic variation. J Pharmacol Ther 2013, 138:103-141.

3. Qiao H-L, Hu Y-R, Tian X, Jia L-J, Gao N, Zhang L-R, Guo Y-Z: Pharmacokinetics of three proton pump inhibitors in Chinese subjects in relation to the CYP2C19 genotype. Eur J Clin Pharmacol 2006, 62:107-112.

4. Weide JVD, Baalen-Benedek EHV, Kootstra-Ros JE: Metabolic ratios of psychotropics as indication of cytochrome P450 2D6/2C19 genotype. Ther Drug Monit 2005, 27:478-483.

5. Yu B-N, Chen G-L, He N, Ouyang D-S, Chen X-P, Liu Z-Q, Zhou HH: Pharmacokinetic of citalopram in relation to genetic polymorphism of CYP2C19. Drug Metabol Dispos 2003, 31(10):1255-1259.

6. Mrazek DA, Biernacka JM, O'Kane DJ, Black JL, Cunningham JM, Drews MS, Snyder KA, Stevens SR, Rush AJ, Weinshilboum RM: CYP2C19 variation and citalopram response. Pharmacogenet Genomics 2011, 21:1-9.

7. Wang G, Lei HP, Li Z, Tan Z-R, Guo D, Fan L, Chen Y, Hu D-L, Wang D, Zhou $\mathrm{H}-\mathrm{H}$ : The CYP2C19 ultra rapid metabolizer genotype influences the pharmacokinetics of voriconazol in healthy male volunteers. Eur J Clin Pharmacol 2009, 65:281-285.

8. Sibbing S, Koch W, Gebhard D, Schuster T, Braun S, Stegherr J, Morath T, Scho"mig A, Beckerath NV, Kastrati A: Cytochrome 2C19*17 allelic variant, platelet aggregation, bleeding events, and stent thrombosis in clopidogrel-treated patients with coronary stent placement. Circulation 2010, 121:512-518.

9. Hulot JS, Collet JP, Silvain J, Pena A, Bellemain-Appaix A, Barthélémy O, Cayla G, Beygui F, Montalescot G: Cardiovascular risk in clopidogreltreated patients according to cytochrome P450 2C19*2 loss-of-function allele or proton pump inhibitor coadministration: a systematic meta-analysis. J Am Coll Cardiol 2010, 56(2):134-143.

10. Mathijssen RHJ, Schaik RHN: Genotyping and phenotyping cytochrome P450: Perspectives for cancer treatment. Eur J Cancer 2006, 42:141-148.

11. Gabriella Scordo M, Caputi AP, D'Arrigo C, Fava G, Spina E: Allele and genotype frequencies of CYP2C9, CYP2C19 and CYP2D6 in an Italian population. Pharmacol Res 2004, 50:195-200.

12. Ingelman-Sundberg M, Sim SC, Ingelman-Sundberg A, Rodriguez-Antona C: Influence of cytochrome P450 polymorphism on drug therapies: Pharmacogenetic and clinical aspects. Pharmacol Ther 2007, 116:496-526.

13. Chaudhry AS, Kochhar R, Kohli KK: Genetic polymorphism of CYP2C19 \& therapeutic response to proton pump inhibitors. Indian J Med Res 2008, 127(6):521-530.

14. Lee S-J, Kim W-Y, Kim H, Shon J-H, Lee SS, Shin J-G: Identification of new CYP2C19 variants exhibiting decreased enzyme activity in the metabolism of S-Mephenytoin and Omeprazole. Drug Metab Dispos 2009, 37(11):2262-2269.

15. Li-Wan-Po A, Girard T, Farndon P, Cooley C, Lithgow J: Pharmacogenetics of CYP2C19: functional and clinical implications of a new variant CYP2C19*17. Br J Clin Pharmacol 2010, 69(3):222-230.

16. Rosemary J, Adithan C, Padmaja N, Shashindran CH, Gerard N, Krishnamoorthy R: The effect of the CYP2C19 genotype on the hydroxylation index of Omeprazole in south Indians. Eur J Clin Pharmacol 2005, 61:19-23.

17. Sim SC, Risinger C, Dahl ML, Aklillu E, Christensen M, Bertilsson L, IngelmanSundberg M: A common novel CYP2C19 gene variant causes ultrarapid drug metabolism relevant for the drug response to proton pump inhibitors and antidepressants. Clin Pharmacol Ther 2006, 79:103-113. 
18. Anichavezhi D, Roa C, Shewade DG, Krishnamoorthy R, Adithan C: Distribution of CYP2C19*17 allele and genotype in an Indian population. J Clin Pharmacy Ther 2012, 37:313-318.

19. Pedersen RS, Brasch-Andersen C, Sim SC, Bergmann TK, Halling J, Petersen MS, Weihe P, Edvardsen H, Kristensen VN, Brøsen K, Ingelman-Sundberg M: Linkage disequilibrium between the CYP2C19*17 allele and wide type CYP2C8 and CYP2C9 alleles: identification of CYP2C haplotypes in healthy Nordic population. Eur J Clin Pharmacol 2010, 66:1199-1205.

20. Sugimito K, Uno T, Yamazaki H, Tateishi T: Limited frequency of the CYP2C19*17 allele and its minor role in a Japanese population. $\mathrm{Br} J \mathrm{Clin}$ Pharmacol 2008, 65(3):437-439.

21. Sakai T, Aoyama N, Kita T, Sakaeda T, Nishiguchi K, Nishitora Y, Hohda T, Sirasaka D, Tamura T, Tanigawara Y, Kasuga M, Okumura K: CYP2C19 genotype and pharmacokinetics of three proton pump inhibitors in healthy subjects. Pharm Res 2001, 18(6):72-77.

22. Cho H, Choi MK, Cho DY, Yeo CW, Jeong HE, Shon JH, Lee JY: Effect of CYP2C19 genetic polymorphism on pharmacokinetics and pharmacodynamics of a new proton pump inhibitor, ilaprazole. J Clin Pharmacol 2012, 52(7):976-984.

23. Ammon S, Treiber G, Kees F, Klotz U: Influence of age on the steady state disposition of drugs commonly used for the eradication of Helicobacter pylori. Aliment Pharmacol Ther 2000, 14(6):759-766.

24. Ishizawa Y, Yasui-Furukori N, Takahata T, Sasaki M, Tateishi T: The effect of aging on the relationship between the cytochrome P450 2C19 genotype and Omeprazole pharmacokinetics. Clin pharmacokinetics 2005, 44:1179-1189.

25. Chong E, Ensom M: Pharmacogenetics of the Proton Pump Inhibitors: $A$ Systematic Review. Pharmacotherapy 2003, 23(4):460-471.

26. Isaza C, Henao J: Isaza Martínez J H, Sepúlveda Arias J, Beltrán L: Phenotype-genotype analysis of CYP2C19 in Colombian mestizo individuals. BMC Clin Pharmacol 2007, 7(6):1-5.

27. Ramsjö M, Aklillu E, Bohman L, Ingelman-Sundberg M, Roh HK: CYP2C19 activity comparison between Swedish and Koreans: effect of genotype, sex, oral contraceptive use and smoking. Eur J Clin Pharmacol 2010, 66:871-877

28. Niioka T, Uno T, Sugimoto K, Sugawara K, Hayakari M, Tateishi T: Estimation of CYP2C19 activity by the Omeprazole hydroxylation index at a single point in time after intravenous and oral administration. Eur J Clin Pharmacol 2007, 63(11):1031-1038.

29. Xie HG, Huang SL, Xu ZH, Xiao ZS, He N, Zhou HH: Evidence for the effect of gender on activity of (S)-mephenytoin 4'-hydroxylase (CYP2C19) in a Chinese population. Pharmacogenetics 1997, 7(2):115-119.

30. Laine K, Tybring G, Bertilsson L: No sex-related differences but significant inhibition by oral contraceptives of CYP2C19 activity as measured by the probe drugs mephenytoin and Omeprazole in healthy Swedish white subjects. Clin Pharmacol Ther 2000, 68(2):151-159.

31. Rezk NL, Brown KC, Kashuba ADM: A simple and sensitive bioanalytical assay for simultaneous determination of Omeprazole and its three major metabolites in human blood plasma using RP-HPLC after a simple liquid-liquid extraction procedure. J Chromatogr B 2006, 844:314-321.

32. Miller SA, Dykes DD, Polesky HF: A simple salting out procedure for extracting DNA from human nucleated cells. Nucleic Acids Res 1988, 16:1215.

33. De Morais SM, Wilkinson GR, Blaisdell J, Nakamura K, Meyer UA, Goldstein $J A$ : The major genetic defect responsible for the polymorphism of S-mephenytoin metabolism in humans. J Bio Chem 1994, 269(22):15419-15422.

34. Qiang M, Anthony YHL: Pharmacogenetics, Pharmacogenomics, and Individualized Medicine. Pharmacol Rev 2011, 63:2437-2459.

35. Justenhoven C, Hamann U, Pierl CB, Baisch C, Harth V, Rabstein S, Spickenheuer A, Pesch B, Brüning T, Winter S, Ko YD, Brauch H: CYP2C19*17 is associated with decreased breast cancer risk. Breast Cancer Res Treat 2009, 115(2):391-396.

36. Musumba CO, Jorgensen A, Sutton L, Eker DV, Zhang E, Hara NO, Carr DF, Pritchard DM, Pirmohamed M, Eker DV, Zhang E, Hara NO, Carr DF, Pritchard DM, Pirmohamed M: CYP2C19*17 Gain-of-function polymorphism is associated with peptic ulcer disease. Clin Pharmacol Ther 2013, 93(2):195-203.

37. Li Y, Tang HL, Hu YF, Xie HG: The gain-of-function variant CYP2C19*17: a double-edged sword between thrombosis and bleeding in clopidogrel-treated patients. J Thromb Haemost 2012, 10(2):199-206.
38. Schroth W, Antoniadou L, Fritz P, Schwab M, Muerdter T, Zanger UM, Simon W, Eichelbaum M, Brauch $\mathrm{H}$ : Breast cancer treatment outcome with adjuvant tamoxifen relative to patient CYP2D6 and CYP2C19 genotypes. J Clin Oncol 2007, 25(33):5187-5193.

39. Ragia G, Arvanitidis KI, Tavridou A, Manolopoulos VG: Need for reassessment of reported CYP2C19 allele frequencies in various populations in view of CYP2C19*17 discovery: the case of Greece. Pharmacogenomics 2009, 10(1):43-49.

40. Gurbel PA, Shuldiner AR, Bliden KP, Ryan K, Pakyz RE, Tantry US: The relation between CYP2C19 genotype and phenotype in stented patients on maintenance dual antiplatelet therapy. Am Heart J 2011, 161:598-604

41. Gumus E, Karaca O, Babaoglu MO, Baysoy G, Balamtekin N, Demir H, Uslu N, Bozkurt A, Yuce A, Yasar U: Evaluation of lansoprazole as a probe for assessing cytochrome P450 2C19 activity and genotype-phenotype correlation in childhood. Eur J Clin Pharmacol 2012, 68(5):629-636.

42. Tamminga WJ, Wemer J, Oosterhuis B, Weiling J, Wilffert B, de Leij LF, de Zeeuw RA, Jonkman JH: CYP2D6 and CYP2C19 activity in a large population of Dutch healthy volunteers: indications for oral contraceptive-related gender differences. Eur J Clin Pharmacol 1999, 55(3):177-184

43. Hägg S, Spigset O, Dahlqvist R: Influence of gender and oral contraceptives on CYP2D6 and CYP2C19 activity in healthy volunteers. Br J Clin Pharmacol 2001, 51(2):169-173.

44. Zand N, Tajik N, Moghaddam AS, Milanian I: Genetic polymorphisms of cytochrome P450 enzymes 2C9 and 2C19 in a healthy Iranian population. Clin Exp Pharmacol Physiol 2007, 34(1-2):102-105.

45. Akhlaghi A, Shirani S, Ziaie N, Pirhaji O, Yaran M, Shahverdi G, Sarrafzadegan N, Khosravi A, Khosravi E: Cytochrome P450 2C19 Polymorphism in Iranian Patients with Coronary Artery Disease. ARYA Atheroscler 2011 7(3):106-110.

46. Saeed LH, Mayet AY: Genotype-Phenotype analysis of CYP2C19 in healthy Saudi individuals and its potential clinical implication in drug therapy. Int J Med Sci 2013, 10:1497-1502.

47. Tassaneeyakul W, Tawalee A, Tassaneeyakul W, Kukongaviriyapan V, Blaisdell J, Goldstein JA, Gaysornsiri D: Analysis of the CYP2C19 polymorphism in a North-eastern Thai population. Pharmacogenetics 2002, 12:221-225

48. Zendedel N, Biramijamal F, Hossein-Nezad A, Zendedel N, Sarie H, Doughaiemoghaddam M, Pourshams A: Role of Cytochrome P450 2C19 genetic polymorphism in the therapeutic efficacy of omeprazole in Iranian patients with erosive reflux esophagitis. Arch Iran Med 2010, 13(5):406-412

49. Gonzalez HM, Romero EM, Peregrina AA, de J Chavez T T, Escobar-Islas E, Lozano F, Hoyo-Vadillo C: CYP2C19- and CYP3A4-dependent Omeprazole metabolism in West Mexicans. J Clin Pharmacol 2003, 43:1211-1215.

50. Kimura M, leiri I, Wada Y, Mamiya K, Urae A, limori E, Sakai T, Otsubo K, Higuchi S: Reliability of the omeprazole hydroxylation index for CYP2C19 phenotyping: possible effect of age, liver disease and length of therapy. Br J Clin Pharmacol 1999, 47(1):115-119.

51. Williams ML, Bhargava P, Cherrouk I, Marshall $J$, Flockhart DA, Wainer IW: A discordance of the cytochrome P450 2C19 genotype and phenotype in patients with advanced cancer. Br J Clin Pharmacol 2000, 49(5):485-488

52. Helsby NA, Lo WY, Sharples K, Riley G, Murray M, Spells K, Dzhelai M, Simpson A, Findlay M: CYP2C19 pharmacogenetics in advanced cancer: compromised function independent of genotype. Br J Cancer 2008, 99(8):1251-1255.

53. Hagymási K, Müllner K, Herszényi L, Tulassay Z: Update on the pharmacogenomics of proton pump inhibitors. Pharmacogenomics 2011 12(6):873-888.

54. Yamazaki $H$, Inoue $K$, Shaw PM, Checovich WJ, Guengerich FP, Shimada T: Different contributions of cytochrome P450 2C19 and 3A4 in the oxidation of omeprazole by human liver microsomes: effects of contents of these two forms in individual human samples. J Pharmacol Exp Ther 1997, 283(2):434-442.

doi:10.1186/s40199-014-0081-6

Cite this article as: Payan et al:: Hydroxylation index of omeprazole in relation to CYP2C19 polymorphism and sex in a healthy Iranian population. DARU Journal of Pharmaceutical Sciences 2014 22:81. 